\title{
Prevalence of Attention-Deficit/Hyperactivity Disorder Among Primary School Children in Oforikrom, Ghana Based on the Disruptive Behavior Disorders Rating Scale
}

\author{
R Anokye, E Acheampong, A Edusei, I Owusu, WK Mprah
}

\begin{abstract}
Objective: To determine the prevalence of attention-deficit/hyperactivity disorder (ADHD) among primary school children in Oforikrom, Kumasi, Ghana.

Methods: 10 of 35 primary schools in Oforikrom were readily available. Of 2000 children aged 5 to 13 years selected, 1540 (77\%) of their parents/guardians consented to participate. Their parents/guardians and six teachers from each school were asked to complete the Disruptive Behavior Disorders Rating Scale to screen children for the presence of ADHD, oppositional defiant disorder, or conduct disorder. Children who displayed symptoms (pretty much or very much) in most related items as determined by parents and/or teachers were considered positive cases.

Results: The mean age of 1540 pupils was $9 \pm 2.16$ years. Most $(31 \%)$ were primary 4 pupils. $5 \%$ of pupils displayed ADHD symptoms (attention deficit disorder subtype in 36\%, hyperactivity disorder subtype in $27 \%$, and combined subtype in $37 \%$ ). Of them, $51 \%$ were male. Most (19\%) of those who displayed the symptoms were in primary 5 .

Conclusion: The prevalence of ADHD among primary school children in Oforikrom was $5 \% .51 \%$ of those with ADHD symptoms were male. Most (19\%) of those with ADHD symptoms were in primary 5.
\end{abstract}

Key words: Attention deficit disorder with hyperactivity; Child; Ghana; Prevalence

Reindolf Anokye, School of Medical and Health Sciences, Edith Cowan University, Joondalup, WA, Australia.

Enoch Acheampong, Centre for Disability and Rehabilitation Studies, Department of Health Promotion, Education and Disability, Kwame Nkrumah University of Science and Technology, Kumasi, Ghana

Anthony Edusei, Department of Community Health, Kwame Nkrumah University of Science and Technology, Kumasi, Ghana

Isaac Owusu, Centre for Disability and Rehabilitation Studies, Department of Health Promotion, Education and Disability, Kwame Nkrumah University of Science and Technology, Kumasi, Ghana

Wisdom Kwadwo Mprah, Centre for Disability and Rehabilitation Studies, Department of Health Promotion, Education and Disability, Kwame Nkrumah University of Science and Technology, Kumasi, Ghana

Address for correspondence: Reindolf Anokye, School of Medical and Health Sciences, Edith Cowan University, Joondalup, WA, Australia.

Email:reindolfanokye@yahoo.com

Submitted: 10 January 2019 Accepted: 10 January 2020

\section{Introduction}

Attention-deficit/hyperactivity disorder (ADHD) is a common behavioural disorder in children and affects about $3 \%$ to $7 \%$ of school-age pupils. ${ }^{1}$ It is characterised by impulsivity, hyperactivity, cognitive/behaviour or emotional deficits, and inattention symptoms that may manifest as hyperactive. ${ }^{2}$ Its worldwide prevalence is between $2 \%$ and
$7 \%$, with an average of around 5\%. ${ }^{3}$ In the United States, about $1 \%$ to $6 \%$ of school-aged children are hyperactive, ${ }^{4}$ and approximately $3 \%$ to $7 \%$ of children have ADHD. ${ }^{5}$ In the England and Wales, 5\% of school-aged children aged 6 to 16 years have some form of the hyperactive disorder. ${ }^{6}$ In Saudi Arabia, $13.5 \%$ of primary school children are hyperactive, ${ }^{7}$ whereas in Nigeria, the prevalence is $8.7 \%$ among children aged 7 to 12 years. ${ }^{8}$ In Ghana, the prevalence of ADHD among children varies from $7 \%{ }^{9}$ to $12.8 \% .^{10}$

A hyperactive disorder can affect every aspect of the children's life as well as their parents' and teachers'. ${ }^{11}$ Such children's behaviour may disrupt school and home settings, and they are likely to display explorative, inquisitive, playful, restless, impulsive, and overactive characteristics. ${ }^{11,12}$

People with ADHD are easily distracted by irrelevant stimuli that frequently interrupt ongoing tasks, and they are likely to attend to trivial noises or events that may be simply overlooked by someone without the disorder. ${ }^{13}$ They have difficulty remaining seated and usually get up frequently. They fidget with objects, tap their hands, and shake their feet or legs excessively. They often get up from the table during meals, while watching television, or while doing homework; they talk excessively, and they make excessive noise during quiet activities. ${ }^{14}$ This study aims to determine the prevalence of ADHD among primary school children in Oforikrom, Kumasi, Ghana. 


\section{Methods}

This cross-sectional study was approved by the Ethics Committee on Human Research Publication at the Kwame Nkrumah University of Science and Technology (Ref: CHRPE/AP/074/18). Informed consent was obtained from parents/guardians of each participant. There was no monetary incentive for participation, and participants were anonymised.

Oforikrom has 35 primary schools with approximately 14,000 pupils, 245 teaching staff, and 35 headteachers. Multi-stage sampling was used. To achieve a confidence level of $95 \%$ with a margin of error of $0.05,32$ of the 35 schools should be selected. ${ }^{15}$ However, only 10 schools were readily available, with an estimated sample size of 4000 pupils. To ensure a representative sample of the study population, we proportionally sampled half of subjects from each stratum (school) until the minimum sample size of 2000 was reached.

Of 2000 pupils aged 5 to 13 years selected, 1540 (77\%) of their parents/guardians consented to participate. Between December 2017 and March 2018, their parents/guardian and six teachers from each school were asked to complete a structured questionnaire to collect sociodemographic data of pupils and the Disruptive Behavior Disorders Rating Scale to screen children for the presence of ADHD, oppositional defiant disorder, or conduct disorder. The scale has been proved reliable and valid in different studies. ${ }^{16,17}$

The scale includes 45 questions that describe the child's behaviour in terms of hyperactivity/impulsivity, inattention, combination of both, oppositional defiant disorder, and conduct disorder. Both parents/guardians and teachers were asked in each question the degree of the child's behaviour: 'not at all', 'just a little', 'pretty much', and 'very much'. Children who displayed symptoms (pretty much or very much) in most related questions as determined by parents and/or teachers were considered positive cases. The scale took 5 to 10 minutes to complete. Data were analysed using SPSS (version 21.0, IBM, USA).

\section{Results}

The mean age of 1540 pupils was $9 \pm 2.16$ years. Most (31\%) were primary 4 pupils. $5 \%$ of pupils displayed ADHD symptoms (attention deficit disorder subtype in $36 \%$, hyperactivity disorder subtype in $27 \%$, and combined subtype in $37 \%$ ). Of them, $51 \%$ were male. Most (19\%) of those who displayed the symptoms were in primary 5 (Table).

\section{Discussion}

ADHD is a common neuropsychiatric disorder among school children. ${ }^{18}$ According to the Centres for Disease Control and Prevention,,$^{19}$ the mean ages for the diagnosis of mild, moderate, and severe hyperactive disorders are 8 years, 7 years, and 5 years, respectively. The worldwide prevalence rates for ADHD are estimated to be 3\% to $7 \%$ among children. ${ }^{20}$ In the present study, $5 \%$ of the primary school children displayed ADHD symptoms, consistent with the 5\% reported among children in England ${ }^{6}$ and Germany. ${ }^{21}$ Nonetheless, a higher prevalence of $7 \%$ was reported in another study in Ghana, ${ }^{10} 6.8 \%$ by Centers for Disease Control and Prevention in 2015, ${ }^{19} 8 \%$ among children

Table. Prevalence of attention-deficit/hyperactivity disorder symptoms among primary school children by sex, age, and class

\begin{tabular}{|c|c|c|c|c|c|}
\hline Variable & $\begin{array}{l}\text { No. (\%) of children } \\
\qquad(\mathrm{n}=1540)^{*}\end{array}$ & Negative $^{*}$ & Positive $(\mathbf{n}=70)^{*}$ & $\mathrm{X}^{2}(\mathrm{DF})$ & p Value \\
\hline Sex & & & & $1.76(1)$ & 0.169 \\
\hline Male & $776(52)$ & $740(51)$ & $36(51)$ & & \\
\hline Female & $764(48)$ & $730(49)$ & $34(49)$ & & \\
\hline Age, $y$ & & & & $2.67(1)$ & 0.129 \\
\hline $6-7$ & 387 (26) & $370(97)$ & $17(24)$ & & \\
\hline $8-9$ & 407 (35) & 392 (95) & $15(21)$ & & \\
\hline $10-11$ & 384 (24) & 364 (93) & $20(29)$ & & \\
\hline$\geq 12$ & $362(15)$ & $344(94)$ & $18(26)$ & & \\
\hline Class & & & & $12.11(1)$ & 0.121 \\
\hline Primary 1 & $232(6)$ & $220(15)$ & $12(17)$ & & \\
\hline Primary 2 & $240(9)$ & $229(15)$ & $11(16)$ & & \\
\hline Primary 3 & $260(18)$ & $248(17)$ & $12(17)$ & & \\
\hline Primary 4 & $289(31)$ & 277 (19) & $12(17)$ & & \\
\hline Primary 5 & $259(18)$ & $246(17)$ & $13(19)$ & & \\
\hline Primary 6 & $260(18)$ & $250(17)$ & $10(14)$ & & \\
\hline
\end{tabular}

Data are presented as No. (\%) of children 
in Puerto Rico, ${ }^{22}$ and $13.5 \%$ in a study in Saudi Arabia. ${ }^{7}$ However, a prevalence of $<5 \%$ has also been reported. ${ }^{23-25}$ The difference in prevalence between studies could be attributed to differences in methodologies, classification systems, definitions, or age range of participants. The prevalence of ADHD is higher in males than in females, according to a review of 44 studies $^{26}$ and the Centers for Disease Control and Prevention. ${ }^{19}$

There are limitations to the present study. Participants were seen only once. There was no further clinical test to confirm the presence of ADHD such as the Swanson, Nolan, and Pelham Rating Scale (SNAP-IV), SNAP-IV Scoring, SNAP DSM-5, and SNAP \& SWAN website.

\section{Conclusion}

The prevalence of ADHD among primary school children in Oforikrom was $5 \% .51 \%$ of those with ADHD symptoms were male. Most (19\%) of those with ADHD symptoms were in primary 5 .

\section{Acknowledgements}

We thank those who rendered their time, support, and assistance to this study. Special thanks to the Ghana Education Service and its officials in the Ashanti region and all headteachers, teachers, and parents for their permission.

\section{Declaration}

The authors have no conflict of interest to disclose.

\section{References}

1. American Psychiatric Association. Diagnostic and Statistical Manual of Mental Disorders; DSM-III. Washington DC. 1980.

2. Dreyer BP. The diagnosis and management of attention-deficit/ hyperactivity disorder in preschool children: the state of our knowledge and practice. Curr Probl Pediatr Adolesc Health Care 2006;36:630. Crossref

3. Sayal K, Prasad V, Daley D, Ford T, Coghill D. ADHD in children and young people: prevalence, care pathways, and service provision. Lancet Psychiatry 2018;5:175-86. Crossref

4. Goldstein S, Goldstein M. Managing Attention Deficit Hyperactivity Disorder in Children: A Guide for Practitioners. John Wiley \& Sons; 1998.

5. DuPaul GJ, Stoner G. ADHD in the Schools: Assessment and Intervention Strategies. Guilford Publications; 2014.

6. National Institute for Clinical Excellence. Methylphenidate, Atomoxetine and Dexamfetamine for Attention Deficit Hyperactivity Disorder (ADHD) in Children and Adolescents. NICE; 2006.

7. Abu Taleb RA, Farheen A. A descriptive study of attention deficit hyperactivity disorder in Sabia City, Saudi Arabia. Int J Cur Res Rev 2013;5:36-41.

8. Adewuya AO, Famuyiwa OO. Attention deficit hyperactivity disorder among Nigerian primary school children: prevalence and co-morbid conditions. Eur Child Adolesc Psychiatry 2007;16:10-5. Crossref

9. Ntiakoh-Ayipah D, Dogbe JA, Peprah Opoku M, Twum F, Owusu M,
Hammond CK, et al. Prevalence of attention deficit hyperactivity disorder among pupils in primary schools in Ghana. J Int Spec Needs Educ 2018. Crossref

10. Afeti K, Nyarko SH. Prevalence and effect of attention-deficit/ hyperactivity disorder on school performance among primary school pupils in the Hohoe Municipality, Ghana. Ann Gen Psychiatry 2017;16:11. Crossref

11. Uwe E. Early identification and management strategies of attentiondeficit/hyperactive disorder in children. Except Child 2000;4:30-3.

12. Agbu JO. Assessment and management of attention-deficit/ hyperactivity disorder of children. In: Nnachi RO, Ezeh PS, editors. The Behaviour of the Nigeria Child. A publication of the Nigerian Society for Educational Psychologist. 2003: 123-32.

13. Randmäe D. Relationship between activity and attention disorder symptoms with school attendance, depression and anxiety in adolescent schoolchildren (doctoral dissertation).

14. Turketi N. Teaching English to Children with ADHD. MA TESOL Collection; 2010.

15. Dadzie AM. Factors influencing primary school attendance and performance in selected schools at Oforikrom sub-metro in Kumasi in the Ashanti region (doctoral dissertation).

16. Friedman-Weieneth JL, Doctoroff GL, Harvey EA, Goldstein LH. The Disruptive Behavior Rating Scale-Parent Version (DBRS-PV): factor analytic structure and validity among young preschool children. J Atten Disord 2009;13:42-55. Crossref

17. Silva RR, Alpert M, Pouget E, Silva V, Trosper S, Reyes K, et al. A rating scale for disruptive behavior disorders, based on the DSM-IV item pool. Psychiatr Q 2005;76:327-39. Crossref

18. Harlacher JE, Roberts NE, Merrell KW. Classwide interventions for students with ADHD: a summary of teacher options beneficial for the whole class. Teach Except Child 2006;39:6-12. Crossref

19. Centers for Disease Control and Prevention. Attention Deficit/ Hyperactivity Disorder. Available at: https://www.cdc.gov/ncbddd/ adhd/features/key-findings-adhd72013.html. Accessed 10 January 2019.

20. Cooper P. Assessing the Social and Educational Value of AD/HD. The Handbook of Social, Emotional and Behavioural Difficulties. 2006; 248-63.

21. Döpfner M, Breuer D, Wille N, Erhart M, Ravens-Sieberer U; BELLA study group. How often do children meet ICD-10/DSM-IV criteria of attention deficit-/hyperactivity disorder and hyperkinetic disorder? Parent-based prevalence rates in a national sample: results of the BELLA study. Eur Child Adolesc Psychiatry 2008;17(Suppl 1):5970. Crossref

22. Canino G, Shrout PE, Rubio-Stipec M, Bird HR, Bravo M, Ramirez $\mathrm{R}$, et al. The DSM-IV rates of child and adolescent disorders in Puerto Rico: prevalence, correlates, service use, and the effects of impairment. Arch Gen Psychiatry 2004;61:85-93. Crossref

23. Gomez R, Harvey J, Quick C, Scharer I, Harris G. DSM-IV AD/HD: confirmatory factor models, prevalence, and gender and age differences based on parent and teacher ratings of Australian primary school children. J Child Psychol Psychiatry 1999;40:265-74. Crossref

24. Zuddas A, Marzocchi GM, Oosterlaan J, Cavolina P, Ancilletta B, Sergeant J. Factor structure and cultural factors of disruptive behaviour disorders symptoms in Italian children. Eur Psychiatry 2006;21:4108. Crossref

25. Polanczyk G, de Lima MS, Horta BL, Biederman J, Rohde LA. The worldwide prevalence of ADHD: a systematic review and metaregression analysis. Am J Psychiatry 2007;164:942-8. Crossref

26. Erskine HE, Ferrari AJ, Nelson P, Polanczyk GV, Flaxman AD, Vos $\mathrm{T}$, et al. Epidemiological modelling of attention-deficit/ hyperactivity disorder and conduct disorder for the Global Burden of Disease Study 2010. J Child Psychol Psychiatry 2013;54:126374. Crossref 